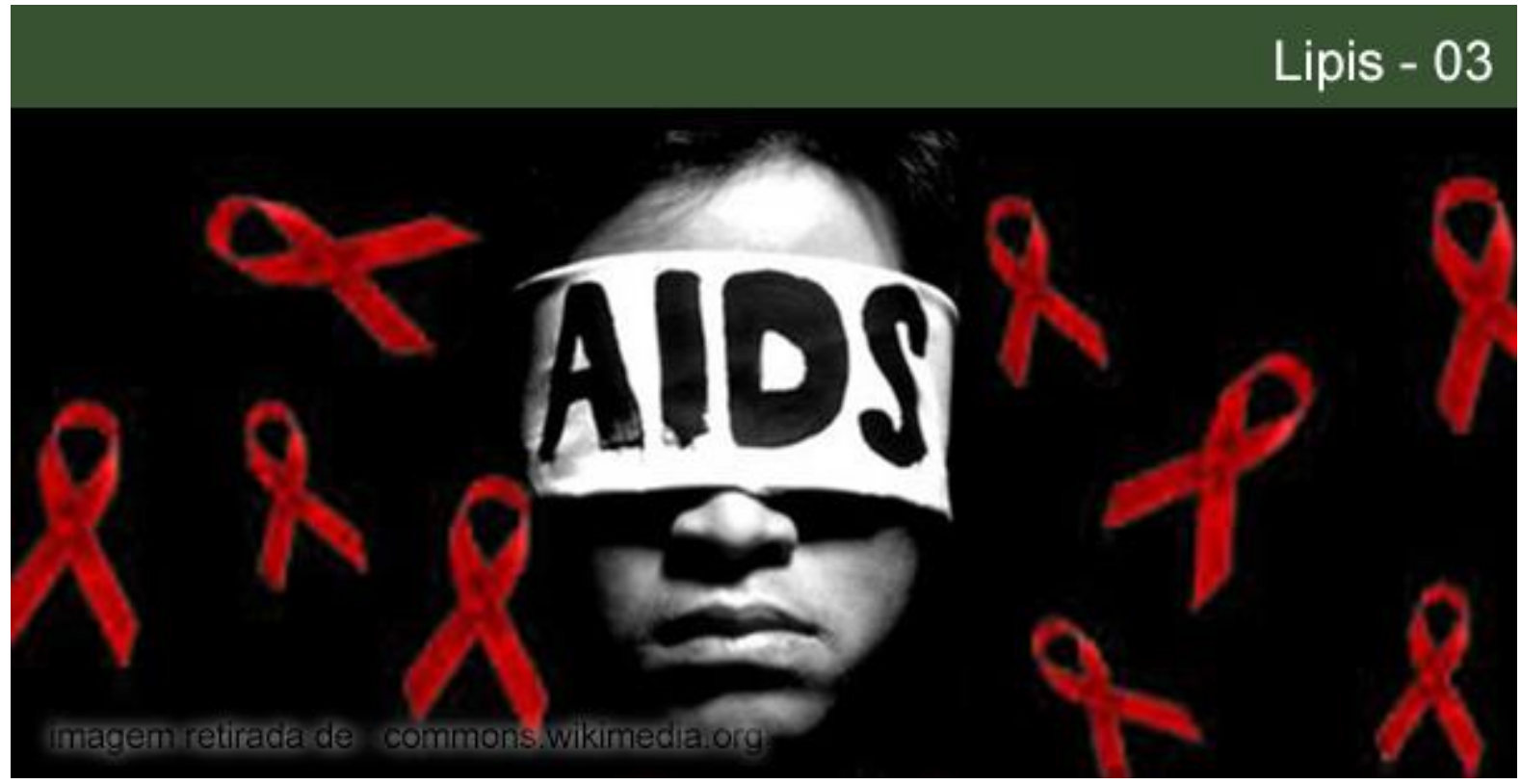

\title{
“QUE É QUE OS HOMENS TEMEM, ACIMA DE TUDO?"' Culpa e vergonha na clínica da Aids
}

\section{Igor Francês}

Psicólogo pela Universidade Federal do Pará - UFPA (2007). Mestre em Psicologia pela UFPA. Atualmente é doutorando do Programa de Pós-Graduação em Psicologia Clínica da Pontifícia Universidade Católica do Rio de Janeiro - PUC-Rio -, e pesquisador pelo Laboratório de Psicanálise e Psicopatologia Fundamental - UFPA. Pesquisador associado do Laboratório Interdisciplinar de Pesquisa e Intervenção Social - LIPIS da PUC-Rio. Bolsista da CAPES. E-mail: igorfrances@yahoo.com.br.

\section{Alessandro Melo Bacchini}

Psicólogo pela Universidade da Amazônia - UNAMA (2009), Mestre em Psicologia Clínica e Social pela Universidade Federal do Pará (UFPA) e Especialista em Psicologia da Saúde/Hospitalar pelo Instituto de Ensino e Pesquisa em Psicologia - IEPS (2011). Atualmente é doutorando em Psicologia Clínica pela Pontifícia Universidade Católica do Rio de Janeiro (PUC-Rio), Pesquisador associado do Laboratório de Psicanálise e Psicopatologia Fundamental (LPPF - Belém/PA) e pesquisador Associado do Laboratório Interdisciplinar de Pesquisa e Intervenção Social (LIPIS/PUC-Rio). Bolsista da CAPES. E-mail: alessandromelobacchini@gmail.com.

Resumo: O objetivo deste texto é fazer uma apresentação do sentimento de culpa e do afeto da vergonha associados à condição de ser portador de HIV/Aids. Apesar de ser um assunto relevante em psicanálise, o tema da vergonha não se configura como algo central na obra freudiana, tendo a culpa um lugar muito melhor definido no que diz respeito à relação do sujeito com a cultura. Pode-se afirmar que, para Freud, a culpa aparece como aspecto do mito fundador de nossa civilização. Em Totem e Tabu, por exemplo, é o sentimento de culpa dos irmãos, após o parricídio, que permite a configuração do pacto social. Se a culpa foi tomada dessa maneira, a vergonha aparece inicialmente como uma força repressora, assim como a moralidade, para depois ser associada, por Freud, ao narcisismo. Dessa forma, pensa-se a vergonha ligada à imagem do sujeito perante a sociedade. Daí, dois fenômenos podem ser discutidos: o medo da exposição e o medo de ser ignorado pelo outro. No que diz respeito à Aids, é importante lembrar que o imaginário sobre a doença constitui-se a partir de um estigma, colocando o sujeito no lugar do estrangeiro. A experiência clínica revela uma tendência a não se nomear a

${ }^{1}$ DOSTOIÉVSKI, Fiódor. Crime e Castigo.

\section{POLÊM!CA | Revista Eletronica da Ueri}


doença, fazendo da Aids algo desconhecido. A vergonha expõe o sujeito e, nesse aspecto, estando ligada a outro tema-tabu (sexo), a Aids demanda, além de uma ressignificação, novos rearranjos para lidar com o corpo e com a sociedade.

Palavras-chave: Culpa. Vergonha. Superego. Narcisismo. Aids.

\title{
WHAT IS THAT THE MEN FEAR ABOVE ALL? Guilt and shame at AIDS clinics
}

\begin{abstract}
The objective of this paper is to show the guilt and affection of shame associated with the condition of being a person with HIV/AIDS. Despite being a relevant subject in psychoanalysis, the theme of shame is not configured as central in Freud's work, the guilt point has a well defined place regarding the relation of the individual with the culture. It can be said that, for Freud, the guilt appears as an aspect of the founding myth of our civilization. In Totem and Taboo, for example, it's the brothers guilt feeling, after the parricide, that allows the configuration of social pact. If the guilt was taken that way, the shame initially appears as a repressive force, such as morality, later to be associated, by Freud, to narcissism. That way, the shame would be related to the image of the individual in front of society. Than, two phenomena can be discussed: the fear of exposure and the fear of being ignored by other. Regarding AIDS, it's important to remember that the imaginary about the disease is constituted from a stigma, putting the individual in the place of the foreign. The clinical experience reveals a tendency to not to mention the disease, making AIDS something unknown. The shame exposes the individual and in that respect, connected to another taboo-theme (sex), AIDS demands, besides a ressignification, new rearrangements to deal with the body and society.
\end{abstract}

Keywords: Guilt. Shame. Superego. Narcissism. AIDS.

\section{Introdução}

Estamos na quarta década da epidemia da aids no Brasil. O avanço tecnológico da ciência fortaleceu, nesse interim, o discurso da medicina, sobrando pouco espaço para problematizar o imaginário social da aids. Mesmo que o tratamento oferecido, nos dias de hoje, melhore a qualidade e aumente a expectativa de vida dos pacientes portadores do vírus, a associação aids e morte marca profundamente a vida de quem recebe o diagnóstico.

As representações da aids como "doença do outro" ainda estão presentes nas explicações morais ou religiosas, implicando mecanismos de negação e de projeção do risco para longe de si próprio - direcionando para homossexuais, prostitutas e travestis, ou para os pecadores, promíscuos, imorais. Na maior parte das vezes, estas representações reforçam a ideia de grupos de risco, tão presente no imaginário social no início da epidemia da aids, ou a ideia de grupos e pessoas mais vulneráveis ao vírus, moralizando seus comportamentos.

$\mathrm{O}$ advento de um novo paradigma para se entender a expansão da epidemia trouxe mudanças conceituais e políticas para o delineamento das estratégias de prevenção e tratamento, mesmo que não se possa negar o caráter extremamente assustador da aids, ainda nos dias de hoje. O imaginário social da aids, ainda é marcado pela associação com a morte, por ser uma doença sem cura.

\section{POLÊM!CA | Revista Eletronica da Uej}


$\mathrm{Na}$ dissertação realizada por Francês (2009), notam-se algumas características intrigantes relacionadas ao diagnóstico e à forma como este é comunicado ao paciente, pois parece haver uma reatualização de um trauma primitivo, que faria o sujeito reviver sua condição de desamparo. Além disso, a manifestação pelo discurso do paciente diante do recebimento desse diagnóstico parece apontar para um sentimento de culpa por questões repetidamente suscitadas, como: "Por que isso está acontecendo comigo? Eu nunca fiz nada de errado..." ou "O que eu fiz para merecer isso?" ou até mesmo "Por que Deus está me castigando dessa maneira?".

Retomando essa discussão, este trabalho se propõe a fazer uma reflexão que envolva dois dos sentimentos que incidem fortemente na fala dos pacientes por nós atendidos: culpa e também vergonha. Notadamente, ambos não se revelam de maneira clara e distinta através da escuta, pois giram em torno do imaginário mortífero supracitado. Para exemplificar, é possível notar em um mesmo paciente a vontade tanto de acabar com a própria vida por se achar culpado pela possível transmissão à sua antiga parceira sexual, quanto a vergonha relacionada aos seus vizinhos por supostos comentários acerca de suas visíveis mudanças físicas.

Apesar de ser um assunto relevante em psicanálise, o tema da vergonha não se configura como algo central na obra freudiana, tendo a culpa um lugar muito melhor definido no que diz respeito à relação do sujeito com a cultura. Se a culpa foi tomada dessa maneira, a vergonha aparece inicialmente como uma força repressora, assim como a moralidade, para depois ser associada, por Freud, ao narcisismo. Dessa forma, pensamos a vergonha ligada à imagem do sujeito perante a sociedade. No que diz respeito à aids, é importante lembrar que o imaginário sobre a doença constitui-se a partir de um estigma, colocando o sujeito no lugar do estrangeiro. A experiência clínica revela uma tendência a não se nomear a doença, fazendo da aids algo desconhecido. A vergonha expõe o sujeito e, nesse aspecto, estando ligada a outro tema-tabu (sexo), a aids demanda, além de uma ressignificação, novos rearranjos para lidar com o corpo e com a sociedade.

É, portanto, a partir de uma articulação entre culpa e vergonha que nos propomos a pensar a aids e o que ela representa na vida psíquica dos pacientes que chegaram a nós, como relato de experiência, entre os anos de 2006 e 2011, atuando nas enfermarias do Hospital João de Barros Barreto, na cidade de Belém do Pará. Duas noções que se articulam não somente na

\section{POLÊM!CA | Revista Eletronica da Uej}


clínica pela via da fala dos pacientes atendidos, mas que, como veremos, permitem pensar sua abrangência como dispositivos de fundação e manutenção do pacto civilizatório.

\section{O que estabelece a culpa?}

A ambiguidade proposital da pergunta apresenta-se justamente para refletirmos sobre dois contingentes extemporâneos que se estabelecem sobre o conceito da palavra culpa. A princípio, cabe ressaltar a que conceito estamos nos referindo. $\mathrm{Na}$ língua portuguesa, o substantivo feminino culpa designa "ato ou omissão repreensível ou criminosa; falta voluntária, delito, crime" e tem por sinônimo a palavra causa. Dessa forma, voltando à pergunta inicial, gostaríamos de refletir sobre tal ambiguidade. A relatividade do pronome, expresso na pergunta inicial, desdobra a significação da palavra e estabelece que, mesmo sendo causa, ela (a palavra) se apresenta como consequência. Causa do que e consequência para quem? - cabem as indagações.

Quando nos propusemos a escrever sobre o sentimento de culpa e sua relação com o diagnóstico positivo para HIV/Aids, possuíamos um acúmulo de questionamentos que, vez ou outra, apareciam nos discursos dos pacientes em atendimento. Vale ressaltar que esses "recortes de fala" foram as molas propulsoras desta investigação, no momento em que as respostas se confundiam com as próprias perguntas. Por outro lado, existia uma espécie de julgamento moral velado - praticado por muitos profissionais -, que nos remetia a algumas décadas de atraso no pensamento social sobre a epidemia da aids.

Esses dois aspectos podem ser resumidos na primeira pergunta: $\mathrm{O}$ que estabelece a culpa? Os dois contingentes extemporâneos por nós sugeridos não estabelecem a culpa nem como causa nem como consequência, ao mesmo tempo em que a estabelecem como as duas coisas. O primeiro diz respeito ao imaginário social da epidemia da aids. Os avanços médicos, as descobertas científicas, as mudanças paradigmáticas sobre a epidemia, é notório, trouxeram modificações significativas no tratamento da doença, ainda que esta se apresente como um problema grave de saúde pública no Brasil. Desde a divulgação do primeiro registro de caso da doença no Brasil, tratou-se de classificar a aids como algo que se reservava a determinados grupos sociais, relacionando a doença a práticas sexuais que iam de encontro a preceitos éticos e morais de nossa sociedade. Tendo clareza que nossa moral sexual não foi alterada nas últimas três décadas, concordamos que o imaginário sobre a aids continua o mesmo. E esse

\section{POLÊM!CA | Revista Eletronica da Ueij}


imaginário incute culpa nos sujeitos portadores de HIV/Aids, ao mesmo tempo em que age como uma voz que faz desses sujeitos vítimas de um comportamento inadequado.

$\mathrm{O}$ segundo contingente diz respeito ao próprio sujeito. Uma ambivalência afetiva se abate sobre seu corpo, agora, marcado pelos estigmas de uma doença e condenado a ser vítima de um castigo sobre um crime que não se sabe qual. O peso desse imaginário construído sobre a aids coloca o sujeito em uma equação mortífera e exige dele a necessidade de rearranjos psíquicos capazes de dar conta de uma nova condição. O diagnóstico positivo que institui a doença (ou o saber sobre a doença) proporciona ao sujeito posicionar-se diante do conflito em uma via de mão dupla: ao mesmo tempo em que o julgamento moral vem de fora - aclarado pela moralidade sobre a manifestação da sexualidade -, ele parte de dentro, vivenciado como sentimento (inconsciente) de culpa e seus desdobramentos.

Em "Totem e tabu" (1913) Freud abordou a questão da culpa através do mito da ordem primeva, em que o advento da cultura aparece como fruto de uma violência primordial. Para Freud, o nosso pecado original é um crime, o parricídio - "ato memorável que foi o começo de tantas coisas: da organização social, das restrições morais e da religião" (p. 168). A partir desse primeiro crime, a culpa encontraria sua origem no retorno do amor sob a forma do remorso; estando o amor, assim, na origem da consciência moral, acompanhado da fatal inevitabilidade do sentimento de culpa. Para Freud, isto se deve à ambivalência em relação ao pai, manifestada por um aspecto agressivo, que se apresentaria através do parricídio, e um aspecto afetuoso, que surge com o remorso. Amor e ódio estão, dessa forma, juntos na fundação do laço social, ou seja, a sociedade é constituída a partir de um conflito em que se insere a trama expressa nas linhas entre a pulsão de vida e a pulsão de morte.

Até aqui, Freud apresenta-nos o antagonismo irremediável entre as exigências da civilização e a moção pulsional, considerando essa incompatibilidade como ameaça frequente à nossa sobrevivência, uma vez que os impulsos agressivos e hostis sempre procuram um meio para se manifestar. É exatamente por isso que a civilização se beneficia do agente interno que vigia o sujeito e o condena com a emergência da culpa.

Em 1923, Freud passa a analisar essa problemática que envolve a noção de sentimento de culpa a partir de uma pré-história individual, ontogenética, retomada pelo Édipo. Segundo ele, esse complexo é um conflito no qual a criança encontra-se dividida entre a realização do desejo incestuoso e a lei que o interdita. Esse conflito estaria representado pelo conflito que se

\section{POLÊM!CA | Revista Eletronica da Uej}


estabelece entre a realização do desejo e a lei, já que a lei não é capaz de fazer a criança deixar de desejar. Porém, a lei é introjetada pela criança como resposta ao medo de perder o objeto de amor ou o amor do objeto.

Essa submissão à lei faz com que a criança assimile tal proibição como sendo psiquicamente sua. Assim, uma parte do eu identifica-se com a figura interditora, enquanto a outra parte continua a desejar. A partir de então, a criança torna-se capaz de encarnar nela mesma, simultaneamente, desejo e lei. Poderíamos argumentar, dessa forma, que a submissão à lei é, também, uma subversão dela. A parte do eu que desempenha a função da lei é o que Freud (1923) chama de supereu.

A função desempenhada pelo supereu, de acordo com o pensamento freudiano, consiste na manutenção da vigilância sobre as ações e as intenções do eu, julgando-as e exercendo a censura. O sentimento de culpa, a severidade do superego - uma das expressões da pulsão de morte na clínica - é, portanto, o medo da severidade que ganha expressão pela consciência (FREUD, 1927, p.139). Marta Gerez-Ambertin (1993) realizou um trabalho rigoroso sobre a noção de supereu na clínica psicanalítica e na cultura, a partir da obra de Freud e Lacan. Para ela desde o nascimento da psicanálise pode ser percebida a tríade: parricídio, culpa e punição, tanto na teoria como na clínica dos primeiros casos de Freud. Dessa forma, os fundamentos teórico-clínicos do superego já estão traçados ao redor desse tríplice eixo, e a noção de consciência moral aparece como a expressão mais primitiva do supereu.

A análise de Cottet (1989), principalmente no que diz respeito à interpretação que Lacan faz do assassinato do pai proposto por Freud, indica o paradoxo presente no mito da ordem primeva. Assim, não somente o assassinato do pai vai abrir caminho ao gozo que a sua presença parece interditar, como também vai reforçar sua interdição. Freud coloca esse paradoxo em evidência no mito da ordem primeva, "confirmando que a inibição é reforçada, ou que os efeitos do supereu são tanto mais fortes quanto o sujeito tenha franqueado o limite dos ideais da moralidade" (COTTET, 1989, p. 8).

$\mathrm{O}$ autor afirma que o que vai dar conta desse sentimento de culpa é, justamente, o amor pelo pai. O surgimento da ideia do supereu, na obra freudiana, como algo criador na origem mesma da lei paterna, em qualquer caso, é um amor que sobrevém após a morte do 
pai. Pode-se dizer, então, que serve de alguma forma como regulação ao desejo (COTTET, 1989).

O aparecimento da noção de supereu na obra freudiana marca, radicalmente, a dependência do sentimento de culpa à sua força punitiva. Isso quer dizer que se renunciar à pulsão aliviava o sujeito da punição externa, com a incorporação da autoridade interna essa possibilidade desaparece. O sentimento de culpa e a tensão permanente entre o eu e o supereu tomam um caráter permanente, ampliando o medo da infelicidade externa, como já havia sido apontado por Freud.

Em $O E$ Eu $e$ o Id (1923), Freud apresenta o Ideal do Eu como uma formação substitutiva que ficou no lugar do sentimento de nostalgia e anseio pelo pai, contendo assim o gérmen a partir do qual todas as religiões se formaram. Ao longo do desenvolvimento da sociedade, o papel do pai foi rendido por professores e autoridades, de modo que as regras e proibições proferidas por estes passam a manter seu poder no Ideal do Eu e exercer a censura moral na forma de uma consciência moral. Dessa forma, a tensão que há entre as exigências da consciência moral e o desempenho do eu acabará por ser vivenciada como sentimento de culpa (FREUD, 1923, p. 47).

O que poderia ser entendido como medo dos pais, medo da castração, (a possibilidade) da perda do amor do objeto ou do objeto de amor, aparece na obra freudiana como consciência culpada (FREUD, 1914). Essa consciência de culpa é apresentada depois como reação a uma pulsão moralmente repudiada (este ponto foi mais detidamente analisado por Freud (1920) em Além do principio de prazer).

Dessa forma, como já foi apresentado, o sentimento de culpa teria uma origem inicial no medo da perda de amor. Assim, o sentimento de culpa consciente estaria intimamente ligado ao pavor de desproteção. Perder o objeto de amor significaria ficar exposto aos perigos, ou seja, ficar desamparado. Podemos perceber, dessa forma, o sentimento de culpa, proposto por Freud, como um fator moral (FREUD, 1923, p. 57) que só se apazigua no estar doente e querer, de modo algum, renunciar ao castigo do sofrimento. O sentimento de culpa seria, então, uma condenação moral ao eu promovida por sua instância crítica, o supereu.

Em O problema econômico do masoquismo (1924), o motor do sentimento de culpa passa estar representado ou ainda identificado com o que para Freud pode ser denominado de masoquismo moral. Diferentemente dos outros dois tipos de masoquismo (erógeno e 
feminino), no masoquismo moral o próprio sofrimento é que importa. Ao passo que as outras formas masoquistas dependem do objeto amado para se instaurar o sofrimento, no masoquismo moral essa vinculação é abandonada, tendo a pulsão se voltado contra o próprio eu.

Freud apresenta a noção de sentimento de culpa inconsciente encontrada na histeria. Para ele, deve-se ao eu o fato de o sentimento de culpa permanecer inconsciente, já que é por meio do recalque que o eu se defende de duas percepções dolorosas: da ameaça de receber a crítica do supereu e da presença de um investimento de carga objetal capaz de gerar sentimentos insuportáveis. A hipótese de Freud é que o sentimento de culpa inconsciente deve-se à circunstância de que a consciência moral surge estritamente ligada ao complexo de Édipo, que, por sua vez, permanece inconsciente. Como seu herdeiro, o supereu é tomado por pulsão de morte, tendo recebido primeiro o componente destrutivo que só depois é dirigido ao eu. Uma das manifestações clínicas que mais intrigou Freud foi o que ele chamou de reação terapêutica negativa.

O sentimento inconsciente de culpa revela-se, então, como uma reação contrária à possibilidade de melhora no tratamento, ou seja, o trabalho analítico esbarra na necessidade de satisfação que o doente estabelece com o sofrimento. Ser punido pelo supereu passa a ser condição psíquica determinante ao eu. É nesse jogo libidinal que se estabelece a força do que Freud chamou de masoquismo moral e, sobretudo, da impossibilidade de melhora. Aqui Freud (1923) observa a atuação da pulsão de morte.

Mas não é somente na reação terapêutica negativa que Freud pode identificar ação da pulsão de morte e sua expressão. O masoquismo moral e sua busca pela autodestruição ganham expressividade nas tendências antissociais. Esse tipo de comportamento seria a consequência de um sentimento de culpa a partir do conflito entre um supereu sádico e o eu submisso. Assim, Freud apresenta o sentimento moral de culpa como sendo a causa, enquanto a criminalidade ou a transgressão, seu representante simbólico.

O que se percebe nesse tipo de afirmação freudiana é a força da determinação psíquica da pulsão de morte. $O$ fato de o sujeito necessitar da punição para satisfazer um desejo inconsciente produz a busca por um poder externo. A necessidade de punição seria, dessa forma, motivação para o ato criminoso. O que Freud salienta é a importância da procura compulsiva pela punição, seja ela por vias internas ou externas. No caso de o conflito entre o

\section{POLÊM!CA | Revista Eletronica da Ueij}


eu e o supereu tomar dimensões insuportáveis ao sujeito, a busca pela punição é perceptível. $\mathrm{O}$ ato ilegal além de acarretar uma interdição e, consequentemente, em um ato exterior punitivo, carrega um profundo alívio ao sentimento inconsciente de culpa. Alívio esse resultante de um afrouxamento do sentimento de culpa proveniente do complexo de Édipo. Para Freud essa talvez tenha sido uma descoberta fundamental para o trabalho analítico.

No Mal Estar da Civilização (1929 [1930]), Freud comenta que na neurose obsessiva há tipos de pacientes que não se dão conta de seu sentimento de culpa, ou apenas o sentem como um mal estar atormentador. Ele nos mostra, assim, que o sentimento de culpa nada mais é do que uma variedade topográfica da angústia, coincidindo com o medo do supereu. Nesse momento da teoria freudiana, aparece a ideia de uma onipresença da culpa, que se manifesta de múltiplas formas e que é fundamentalmente inexpiável.

Neste último texto, Freud destaca o sentimento de culpa como o mais importante problema no desenvolvimento da civilização, traçando uma verdadeira genealogia da culpa, ao demonstrar as diversas etapas de sua constituição, da angústia social ao sentimento inconsciente de culpa. Nessa perspectiva, Freud define uma primitiva forma de culpa, caracterizada pelo medo de perder o amor dos pais (o que já havia sido enunciado em 1913), como angústia social. Na elaboração do Complexo de Édipo, a autoridade internalizada, com a formação do supereu, transforma-se em consciência ou sentimento de culpa, que aparece como uma permanente infelicidade interna.

\section{E a vergonha?}

A relação estabelecida até o momento entre culpa e aids remonta à ruptura estabelecida no diagnóstico, justamente por colocar o indivíduo frente ao "pecado" cometido como afronta à moralidade. O diagnóstico, porém, parece se expressar através do corpo, circunscrito em representações que remetem a um imaginário sobre a epidemia da aids. Dessa forma, cremos ser interessante tratar de outro tema nesse trabalho. Se socialmente a aids marca o corpo como um estigma, colocando o sujeito diante de sua própria finitude; a aids, enquanto representação, apresenta outras marcas. O trauma reinscrito precisa ser ocultado de uma cultura de prisão imaginária que ainda discrimina e marginaliza, assujeitando o paciente em um lugar vertiginosamente posto entre vítima e culpado. Por estar ligado ao outro tema-

\section{POLÊM!CA | Revista Eletronica da Ueri}


tabu que é o sexo, a aids e a condição que ela provoca ao sujeito, gera sentimentos de vergonha.

O tema da vergonha não foi privilegiado no campo psicanalítico, em termos históricos. Freud, por exemplo, não dedicou sequer um artigo exclusivamente a essa noção. Dessa forma, não é possível circunscrever na sua obra um conceito de vergonha, mesmo que o vocábulo apareça em seus escritos por diversas vezes, ressaltando duas dimensões: uma indicando as dimensões do recalque e da sexualidade, outra orientada por um sentido narcísico.

Nessa primeira concepção, a vergonha era utilizada como equivalente da noção de pudor e agia como força repressora dos representantes pulsionais, agindo como barreira contra o retorno do recalcado. Seguindo o modelo clássico de aparelho psíquico, um objeto inicialmente fonte de prazer se transformaria em objeto de vergonha em virtude da moral sexual civilizada. Presente com uma maior intensidade em indivíduos do sexo feminino, esse tipo de vergonha seria o sinônimo de uma formação reativa à sexualidade, acompanhada frequentemente de reações como nojo e asco frente a certas situações que remetessem ao registro recalcado. Assim, Freud associa vergonha e olhar.

Apesar de a vergonha, nesse contexto, estar mais adequada ao modelo clássico de aparelho psíquico freudiano, erigido em torno da clínica da histeria, é possível perceber uma outra acepção, que, embora menos desenvolvida, encontra-se mais próxima daquilo que observamos na clínica da aids, correlacionada ao narcisismo e à estabilização de uma imagem de si. Assim, vergonha parece estar associada à imagem do sujeito diante da comunidade, já que a ela se associa uma sensação de insuficiência diante de um ideal.

De fato, a escuta no hospital parece atestar uma recorrência da vergonha. Nas palavras de um de nossos pacientes que condensa tais demandas: "Tenho medo de ficar magro demais e de andar mancando. Vão ficar comentando de mim quando eu andar pela minha rua". Assim, é notória a presentificação da vergonha diante de um ideal de saúde não atingido e que para o sujeito, parece ganhar via de expressão imaginariamente fixada nos olhares e comentários de seus outros. Dito de outra maneira, a vergonha parece advir do atestado da falha de um ideal que assombra o sujeito em sua relação com a alteridade.

A aproximação da vergonha com o narcisismo em termos conceituais pode ser percebida quando passamos a considerar dois fenômenos: o medo de exposição e o medo de ser ignorado. Ao mesmo tempo em que o indivíduo deseja ser reconhecido pelo outro como 
objeto de amor, há o temor de não possuir os adjetivos que o outro, supostamente, desejaria que ele tivesse. Ao expor o indivíduo, a vergonha cria uma imagem corporal que é submetida a uma perseguição. Certa vez, foi escutado de um dos pacientes a seguinte indagação: Será que vou ficar parecido com o Cazuza? É o corpo que definha no diagnóstico, a imagem em rascunho que precisa ser redesenhada, pois que se não, morre sem recursos de elaboração.

A vergonha, enquanto uma vitimização do eu por si mesmo, faz da moldura vazia uma face neutra que oculta a existência do sujeito como agente ativo do próprio destino psíquico, caso exista um apego à posição de traído pelo desejo do outro. Lambotte (1993) apresenta a noção de moldura vazia como sendo o modelo especular da melancolia: o olhar da mãe atravessa o bebê para se fixar num ponto para além dele. Esse olhar não recusa a existência do bebê: a mãe sabe que o bebê está ali, simplesmente o que mais lhe interessa não é ele. O olhar que se perde ao longe indicaria um interesse em algo para além dele.

Há por assim dizer uma regulação do valor da autoimagem diante do outro (real ou ideal). Nos espaços comuns e de circulação, essa imagem aparece de forma desqualificada, devendo permanecer escondida do mundo exterior. A vergonha, então, como uma das reguladoras da inserção e permanência do indivíduo na comunidade, reafirma a importância do outro para a construção de identidades, ao ecoar no narcisismo uma ameaça de exclusão do grupo. Assim, pode-se pensar que essa ameaça à identidade, que provoca a vergonha, aparece como aquilo que o indivíduo identifica como diferente da imagem que busca assumir perante o grupo. Essa diferença denuncia uma ruptura entre o que o sujeito é e o que ele imagina que deveria ser para fazer parte do grupo.

Dessa maneira, este aspecto da vergonha distancia o indivíduo de um ideal supostamente compartilhado no grupo, transformando-o em um estranho e o posicionando a uma distância importante dos outros membros da comunidade. A desvalorização da autoimagem é o preço psíquico da ausência de reação à violência narcísica sofrida. Essa impossibilidade de defesa ecoa em um esvaziamento narcísico, uma vez que o embotamento do amor próprio é tributário de uma suposta falha frente ao ideal. Diante disso, o sujeito é remetido a uma impotência radical e adota a companhia de um sentimento inconsolável, sentindo-se vulnerável, desprezível e desprovido de qualquer defesa. Essas "razões" levam o sujeito a não querer nada, pois se sente um nada. O desaparecimento é, então, a única vontade que comporta um narcisismo gravemente ferido.

\section{POLÊM!CA | Revisa Eletronica da uej}




\section{Referências}

COTTET, S. O paradoxo do gozo. Três seminários. Salvador: Fator, 1989.

FRANCÊS, I. HIV, da possibilidade à aceitação: paciente e terapeuta frente ao diagnóstico. Dissertação de mestrado, UFPA, 2011.

FREUD, S. (1913). Totem e tabu. In: Edição Standard Brasileira das Obras Psicológicas Completas. (Vol. XIII). Rio de Janeiro: Imago, 1996.

(1923). O ego e o id. In: Edição Standard Brasileira das Obras Psicológicas Completas. (Vol. XIX). Rio de Janeiro: Imago, 1996.

(1924). O problema econômico do masoquismo. In:

Psicológicas Completas. (Vol. XIX). Rio de Janeiro: Imago, 1996.

Edição Standard Brasileira das Obras

(1927). O mal estar na civilização. In:

Edição Standard Brasileira das Obras Psicológicas

Completas. (Vol. XXI). Rio de Janeiro: Imago, 1996.

GEREZ-AMBERTIN, Marta. Las voces del superyo en la clínica psicoanalítica y en el malestar en la cultura. Buenos Aires: Manantial, 1993.

Recebido em: 30/09/2015.

Aceito em: 13/11/2015. 